been abundant expectoration of thick purulent sputa. An exploratory puncture of the left side procured thick pus.

Operation.-Chloroform having been administered, a shor incision was made into the chest in the fourth intercostal space in the anterior axillary line, and through this a shortly curved rigid urethral sound passed as far as possible down and somewhat backwards, its point being projected in the ninth space in the line of the angle of the scapula, and on it a second incision made; on digital examination the finger entered the pleural cavity, a mass of soft adbesions being perceptible immediately in front of the incision; a large quantity of pus escaped freely. A drainage-tube about three-eighths of an inch in diameter and six inches long having been inserted in the lower opening, the upper wound was closed by sutures; there was little hæmorrhage. The side was dressed with carbolic gauze, the spray having been used throughout. The child had been extremely faint during the later stages of the operation, but revived quickly. The dressing was changed the same evening, the discharge being thin, blood-stained, and profuse; the patient in little pain, warm, and comfortable. Temperature $100.8^{\circ}$

Sept. 12th.--Re-dressed; the dressing contained about four ounces of blood-stained pus, free from odour; the tube clear. The heart's apex was to the left of the sternum. Temperature, morning, $98^{\circ}$; evening, $998^{\circ}$. Expectoration of yellow sputa still continued.

13th.-The upper incision had almost healed; stitches removed and tube shortened. Temperature $99 \cdot 2^{\circ}$.

15th.-Discharge less. The whole of the side was fairly resonant; over the upper half respiration could be well heard, but harsh and accompanied by coarse friction; at the base the breathing was audible, but distant; the heart's impulse was close to the left nipple line, the dulness reaching to the mid-sternum to the right.

16th.- Cough slight, and expectoration much less. Bowels had been extremely constipated. One-tenth of albumen was found in the urine. A mixture containing sulphate and carbonate of magnesia was ordered every morning.

17th.-She had passed a large quantity of uric acid in big crystals. Ordered eight grains of bicarbonate of potash three times daily.

20th. -The discharge had lessened much, and the general condition had much improved. The tube was again shnrtened. A trace of albumen still existed in the urine.

22nd. - The side had fallen in considerably; there was fair resonance all over and free air entrance in the upper twothirds; the apex beat in the fifth space, one inch outside the nipple line. Bowels still very costive. Five minims of liquid extract of cascara sagrada ordered.

25th.-Discharge very scanty. The tube left out.

27 th. - The spray was discontinued. Wound superficial and healing rapidly. There was no evidence of re-collection.

Oct. 5th.-Granulations pale and cedematous; a probe would not pass. She had no cough or expectoration, and felt quite well.

Oa the 2lst the wound had quite healed, and on the 28 th the patient left the hospital. The left sile, sunken considerably, especially over the apex in front, yielded a resonant note of good quality; respiration was heard well all over, and free from adventitious sounds, except some coarse crackling with inspiration at the extreme base. Her temperature never rose higher than $99 \cdot 2^{\circ}$ after Sept. 13th, and albuminuria ceased on the $25 \mathrm{th}$. She continued to pass uric acid occasionally.

Jan. 10th, 1887. - The child attended at the out-patient department. She had gained strength, weight, and colour. The affected side was more flattened anteriorly and posteriorly; breathing was loud and clear to the extreme base.

\section{SEAMEN'S HOSPITAL, GREENWICH.}

SURGICAL CASES OF INTEREST, WITH REMARKS.

$$
\text { (Under the care of Mr. G. R. TuRner.) }
$$

Case 1.--Sequel to a successful case of Fractured Patella treated by Wiring.-William W--, aged twenty-five, a sailor, fractured his right patella whilst at sea. He had no treatment for twelve days, and was then in a foreign hospital for a month. The fracture was treated by strapping and a plaster-of-Paris splint. He left the hospital in a month's time, and then came under the care of Mr. Mayo Robson of Leeds, in June, 1885, four months after the accident. He had an ununited fracture of the patella, with an iach and a half's separation of the fragments. His limb was very weak, and perfectly useless to him. Mr. Robson cut down on the fragments and wired them together. Great difficulty was experienced in approximating them, the lateral expansion of the vasti and the quadriceps requiring division. The wound ran an aseptic course, and be was made an out-patient in September. He could walk freely, could flex his knee nearly to a right angle, but complained of a little pain below and to the outer sirle of the patella. A note says: "This may be due to some of the gold wire sutures which were not removed." 0n leaving Leeds he went to sea, and whilst on board ship fell and hurt his knee again, and was taken to a hospital at Sulina and treated. After this he came to the Seamen's Hospital, Greenwich. He had almost perfect use of his knee, and the patella appeared soundly united. Protruding from a sinus on the outer side of the joint was a wire, which he said had been catching his trousers as he walked since his last accident. There was a little suppuration around. On April 1st he complained of considerable pain in the knee-joint, which became rapidly distended with fluid. His temperature rose to $104^{\circ}$; pulse 128 . The face and body were covered with an erythematous rash. On seeing him the next day, Mr. Turner, with full antiseptic precautions, laid the joint freely open on each side of the patella and introduced a drainage-tube. The fluid that escaped consisted of turbid lymph, hardly to be called purulent. The distension of the joint was very great before the operation. The projecting wire was removed; it could be traced in the cavity of the joint to just below the patella, and was there lost. The man's temperature and pulse rapidly fell nearly to normal after the operation, and the wound ran an aseptic course. His convalescence was interrupted now and then by epileptic fits, to which he was subject. Two other wires became prominent under the skin, and one projected through it. These were dissected out on the 4th of July, and he shortly afterwards was up and about. After he was discharged he again fell down (? in an epileptic fit), and refractured the same patella very close to the insertion of the ligamentum patellæ. This fresh accident brought to light yet another wire, which was removed in September, and the man shortly afterwards left the hospital. He could walk perfectly, and could bend his knee to more than a right angle. He could not, however, perfectly extend it, as there was some slight wasting of the quadriceps-not sufficient, however, to interfere in any way with his activity. It should have been mentioned that his second fracture was treated simply by rest and strapping, the lower fragment being obviously too small for wiring, even had such a proceeding been contemplated.

Remar\%s by Mr. TuRnER.-This case (the notes of which were kindly sent to me by Mr. Mayo Robson) is of interest, I think, as showing how troublesome, and even worse, wires may become if the knee which contains them is subjected, as in this instance, to renewed injury. The man's frequent accidents were no doubt due to his epileptic tendency. His present condition is, on the whole, satisfactory. At one time he was very near having acute suppuration of the knee-joint. Timely incision into the tense distended joint at once reduced his temperature from $104^{\circ}$ to $100^{\circ}$, and materially improved his general condition. The wires were troublesome to remove, and were not finally got rid of for some considerable time. Mr. Mayo Robson used but three gold wires to suture the patella. I must have had to deal with two fragments of on $\theta$ of these. The strength of the osseous union obtained by their means is shown by the second fracture occurring below instead of at the seat of the first.

CaSk 2. Compound Comminuted Fracture of the Ulna into the Elbow-joint; recovery with a movable joint.Wm. C- -, aged thirty, presented himself at the hospital with a wound leading down to a comminuted fracture of the ulna at the junction of the olecranon and coronoid processes due to direct violence. Two loose fragments of bone were removed by enlarging the wound, and the parts and joint were washed out with carboliclotion. The wound ran an aseptic course, and healed shortly after a drainagetube that had been introduced into the joint on his admission was removed. Passive motion was then daily employed. Shortly after commencing this a peri-articular abscess formed, and was opened. A second abscess appeared later on, and was likewise opened. As soon as it was possible passive motion was again practised, and the patient encouraged to use his elbow. He remained in hospital doing 
work about the place for three months or so. Ile suffered from pain referred to the distribution of the ulnar nerve. He was of a very sensitive nature, or there is no doubt his progress would have been more rapid. When last seen the relations of the olecranon to the condyles of the humerus were normal. An inch below this process is an irregular transverse depression indicating the seat of fracture. There is a depressed cicatrix at the site of the old wound, and the bone beneath is somewhat irregular. He can flex the elbow so as to touch his shoulder with the tips of his fingers, and extend it to an angle of $150^{\circ}$. The radius can be rotated, and both flexion and extension are "getting better every day." The joint is very strong; he "can carry four gallons easily," or "with another man can lower thirty gallons of rum." All the symptoms referable to the ulnar nerve have disappeared.

Remarks.-This result to a compound comminuted fracture into the elbow-joint is a very satisfactory one, and better than if a formal excision of the articulation had been practised.

Case 3. Dislocation of the Foot backwards.-Henry Haged sixty, was knocked down in a scuffle, and fell with his right foot under him. On admission, the dorsum of his right foot was considerably shortened and the heel correspondingly lengthened. The foot was at right angles to the leg, and the lower end of the tibia very prominent; the fingers could almost be placed under the anterior edge. The internal malleolus was fractured and carried backwards with the astragalus. Reduction was easily effected by extension and then carrying the foot forwards. The position was then good. The man recovered, with some increased width between the malleoli.

The interest of this case rests solely on the rarity of backward dislocations of the foot.

\section{iftedical Sorieties.}

\section{PATHOLOGICAL SOCIETY OF LONDON.}

Fibroma of Ovarian Liyament.-Metastatic Carcinoma of Prostate.-Large Dermoid Cyst over Sternum.-Gailstone causing Obstruction of Bowel.-Cystic Disease of Testicle.-Multilocular Cystic Epithelioma of Jaw.Cystic Epithelioma of Neck.

As ordinary meeting of this Society was held on Tuesday last, Sir James Paget, F.R.S., President, in the chair.

Mr. Shatrock read for himself and Mr. R.W. Parker the report of the Morbid Growths Committee on Mr. Butlin's case of Recurrent Tumour of the Breast. It had a foliaceous aspect, like some cases of adeno-sarcoma of the breast, but the histological characters of the growth were those of villous carcinoma originating from the ducts, as distinguished from the acini.

Mr. Alban Dopar showed a small Spherical Tumour in the Substance of the Left Ovarian Ligament. A microscopic section was also shown. It proved that the tumour was made up of plain muscular fibres, mingled with white fibrous tissue; in fact, it was a "fibroid" precisely similar to several other fibroid growths which, in this case, were found in the uterus. The ovarian ligament was a prolongation of uterine tissue, its fibres passing into the parenchyma of the ovary. Hence it was subject to fibro-myoma, like the uterus, whence it was derived; and hence, also, fibromyoma was sometimes developed in the ovary into which it ran. It was probable that fibro-myoma of the ovarian ligament had been sometimes mistaken for a so-called supernumerary ovary. In this case the latter condition existed on the right side. - Mr. SHAtTock said that he often had a difficulty in differentiating fibrous tissue from plain muscular tissue in examining ovarian tumours.-Mr. ALBAN DorAN, in reply, said that he sympathised with Mr. Shattock's difficulty, but thought that well-marked nuclei such as might be seen in plain muscular tissue in the uterus of the new-born was diagnostic, and these were also to be found in incipient myoma of the ovary.

Mr. HuRry Fenwick showed a specimen of Metastatic or Secondary Carcinomatous Deposit in the Prostate. He could only find four examples of this class of carcinoma of the gland in medical literature (Mercier, Langstaff, Guyot, and
Lebert). In three of these cases the primary growth was found in the stomach; and in the last the dura mater was the site of the initial deposit. The specimen was removed from a man aged twenty-six, whose first symptom was great lumbar pain. The duration of the entire illness was two months and a half. The spinal cord finally became attacked, and paraplegia ensued. The necropsy revealed the lung to be primarily affected, and the liver, spleen, kidneys, prostate, and cord secondarily. The growth was of the "scirrhoid" type.

Mr. H. H. CLUTron showed a large dermoid cyst removed from over the sternum in October, 1886. The subject of it was a married woman aged thirty-nine. The tumour was noticed at the age of six weeks to be of the size of a pea. At ten years it was tapped, but no fluid withdrawn. At nineteen it was of the size of a hen's egg. It remained stationary for many years, but during the last five years it had grown to twice the size. The tumour hung in a pendulous fashion from the sternum on a level with the breasts, and measured thirteen inches in circumference. The entire cyst was removed. Its lining membrane appeared to be of cutaneous structure, and one hair could be seen projecting from its surface. Microscopically, neither sebaceous glands nor hair follicles could be found. The contents, which measured eleven ounces, were composed of epidermis, cholesterine, and fat.-Mr. F. S. EvE had examined several dermoid cysts which did not contain sebaceous glands or hairs. Dermoid cysts occurred in various situations, as over the scapula, where they were in no relation with the branchial clefts or with the middle line of closure. They originated from displacement of epiblast. - Dr. ANGEI MONEY referred to a case (recorded in the Journal de Médecine de Bour (eau $x$ ) of apparent dermoid cyst communicating with the central canal of the spinal cord at the level of the lower end of the cervical enlargement.-Mr. STEPHEN PAGET said that in hairy chests there was regular parting of the hair at the angulus Ludovici, the hair above growing upwards and below growing downwards.-NIr. J. HUTCHINson, jun., said that he had met with three cases of dermoid fistula in the middle line at the junction of the nose and forehead. - Mr. BLAND SUTTON said that the situations mentioned by Mr. Hutchinson was a common site for meningoceles.-Mr. Hutchinson, jun, said the cases he referred to were undoubtedly dermoid cysts, and not meningoceles. - Sir JAMES PAGET had removed three such growths, and in none was there any connexion with the interior of the skull; but in one case a pedicle extended between the nasal bones. They were undoubtedly dermoid. One case was also associated with a spina bifida. There was sometimes an unusual growth of the dermoid cyst at the time of puberty, when there was a greater activity of the organs derived from epiblast.-Mr. A. A. BowLBY had observed two undoubted dermoid cysts in the area of junction between the nose and forehead.-Mr. CLuTTON said there was no evidence of increased growth until the patient got married. He had removed two dermoid cysts from the forehead at the root of the nose. Such cysts occurred in any part of the body, though most commonly in the middle line or along the lateral fissure.

Dr. Pye-Syite showed a large Gall-stone removed from a lady aged seventy-eight, who had never had jaundice, but suffered from increasing constipation, which culminated in obstruction. Examination per rectum revealed something abnormal, which was regarded as possibly carcinomatous and situated above the sigmoid flexure. It was very movable. After thirteen days' obstruction the stone was passed and the patient remained free from trouble. A second larger stone of cylindical shape was also shown. It came from a woman aged sixty, in whom constipation never proceeded to complete obstruction. The date at which the communication between the duodenum and gall-bladder occurred was unknown.-Mr. J. HAMMERSLFY said that the patient in the first case remained perfectly well.-Mr. SxatTock mentioned a fatal case of complete obstruction from gall-stone. It was an unpublished case of Dr. Bristowe.-Dr. Coupland thought it unlikely that any subsequent difficulty would occur, for the opening into the duodenum from the gall-bladder must be large to have allowed the safe passage of a stone of that magnitude.

Mr. Eve read a paper on Cystic Disease of the Testicle. It was based on a microscopic examination of twel ve selected specimens, and a table of twenty-eight recorded cases in which a microscopic examination had been made. There M 2 